\title{
Global carbon monoxide vertical distributions from spaceborne high-resolution FTIR nadir measurements
}

\author{
B. Barret ${ }^{1, *}$, S. Turquety ${ }^{2, * *}$, D. Hurtmans ${ }^{1}$, C. Clerbaux ${ }^{1,2}$, J. Hadji-Lazaro ${ }^{2}$, I. Bey ${ }^{3}$, M. Auvray ${ }^{3}$, and P.-F. Coheur ${ }^{1}$ \\ ${ }^{1}$ Service de Chimie Quantique et Photophysique, Université Libre de Bruxelles, Bruxelles, Belgium \\ ${ }^{2}$ Service d'Aéronomie, Institut Pierre-Simon Laplace, Paris, France \\ ${ }^{3}$ Ecole Polytechnique Fédérale de Lausanne (EPFL), Lausanne, Switzerland \\ *now at: Laboratoire d'Aérologie, CNRS, Toulouse, France \\ ** now at: Division of Engineering and Applied Sciences, Harvard University, Cambridge, Massachusetts, USA
}

Received: 23 February 2005 - Published in Atmos. Chem. Phys. Discuss.: 11 July 2005

Revised: 18 October 2005 - Accepted: 21 October 2005 - Published: 2 November 2005

\begin{abstract}
This paper presents the first global distributions of $\mathrm{CO}$ vertical profiles retrieved from a thermal infrared FTS working in the nadir geometry. It is based on the exploitation of the high resolution and high quality spectra measured by the Interferometric Monitor of Greenhouse gases (IMG) which flew onboard the Japanese ADEOS platform in 19961997. The retrievals are performed with an algorithm based on the Optimal Estimation Method (OEM) and are characterized in terms of vertical sensitivity and error budget. It is found that most of the IMG measurements contain between 1.5 and 2.2 independent pieces of information about the vertical distribution of $\mathrm{CO}$ from the lower troposphere to the upper troposphere-lower stratosphere (UTLS). The retrievals are validated against coincident NOAA/CMDL in situ surface measurements and NDSC/FTIR total columns measurements. The retrieved global distributions of $\mathrm{CO}$ are also found to be in good agreement with the distributions modeled by the GEOS-CHEM 3D CTM, highlighting the ability of IMG to capture the horizontal as well as the vertical structure of the $\mathrm{CO}$ distributions.
\end{abstract}

\section{Introduction}

Carbon monoxide (CO), produced by human activities such as the combustion of fossil fuels, biomass burning and by the oxidation of $\mathrm{CH}_{4}$ and other hydrocarbons (Holloway et al., 2000), is one of the most important atmospheric pollutants. It is responsible for about $75 \%$ of the hydroxyl radical (OH) sink (Thompson, 1992), and thereby affects the oxidizing capacity of the troposphere and the concentrations of

Correspondence to: B. Barret

(brice.barret@aero.obs-mip.fr) greenhouse gases such as $\mathrm{CH}_{4}$ and $\mathrm{O}_{3}$, and contributes to climate change (Daniel and Solomon, 1998). As a precursor to the formation of tropospheric ozone, $\mathrm{CO}$ also greatly influences air quality. Finally, with a lifetime of 1 to 3 months, $\mathrm{CO}$ is a good tracer to study long range transport of pollution (Forster, 2000; Stohl et al., 2002; Duncan and Bey, 2004).

In the past decades, the abundance of tropospheric $\mathrm{CO}$ was only provided by sparsely distributed measurement sites (Novelli et al., 1992, 1998) and by airborne measurement campaigns (Emmons et al., 2000). Nadir looking instruments placed on polar orbiting satellites to probe the troposphere have greatly enhanced our ability to address the impact of human activities on the evolution of the composition of the atmosphere (Clerbaux et al., 2003).

Global distributions of $\mathrm{CO}$ total columns have been first measured by the nadir viewing thermal infrared gas correlation spectrometer MAPS (Measurement of Air Pollution from Space), which flew onboard space shuttles for short missions in 1981, 1984 and 1994 (Reichle et al., 1999). MOPITT (Measurement Of Pollution In The Troposphere), based on the same principles than MAPS and operating from the Terra satellite since December 1999 provides global CO distributions with some information on its vertical distribution (Deeter et al., 2003). More recently, McMillan et al. (2005) have reported global distributions of $\mathrm{CO}$ in the middle troposphere retrieved from AIRS (Atmospheric Infrared Sounder) launched on the Aqua platform in 2002. The Fourier Transform Spectrometer (FTS) IMG (Interferometric Monitor for Greenhouse gases), which flew onboard the ADEOS platform (Kobayashi et al., 1999) from August 1996 to June 1997 , has already provided CO total columns on a limited period of time (Hadji-Lazaro et al., 1999). In the near future, global tropospheric $\mathrm{CO}$ data will also be

(C) 2005 Author(s). This work is licensed under a Creative Commons License. 
provided by TES (Tropospheric Emission Spectrometer) that has been launched on the Aura satellite in 2004 (Worden et al., 2004) and by the series of IASI (Infrared Atmospheric Sounding Interferometer) instruments, the first of which is planned to be launched on the Metop meteorological platform in 2006 (Turquety et al., 2004). Finally, SCIAMACHY onboard the ENVISAT platform launched in March 2002, which measures the near infrared solar radiation reflected by the Earth's surface, has recently provided its first $\mathrm{CO}$ total columns on a global scale (Buchwitz et al., 2004; Frankenberg et al., 2004). Up to the present date, MOPITT is the only space-borne nadir instrument that has successfully delivered information about the vertical distribution of $\mathrm{CO}$ in the troposphere (Deeter et al., 2004).

This work examines the possibilities to retrieve vertically resolved information from a nadir viewing thermal infrared FTS. The analysis relies on the measurements provided by IMG, which offers a unique source of information to prepare the TES and IASI space missions. Global distributions of CO profiles based on the analysis of the IMG data recorded from 1 to 10 April 1997 are presented for the first time. In Sect. 2 we present the $\mathrm{CO}$ observations including the characteristics of IMG, the retrieval method, the characterization formalism and the main experimental parameters. Section 3 is dedicated to a short description of the three-dimensional (3-D) global model of chemistry and transport GEOS-CHEM, used for the comparison with the IMG CO global distributions. In Sect. 4 the results are presented and discussed, starting with a detailed characterization of the retrieved $\mathrm{CO}$ profiles in terms of vertical sensitivity and error budget. The retrieved total columns and lower tropospheric mixing ratios of $\mathrm{CO}$ are then compared with ground-based and in situ surface measurements. Finally, the CO global distributions retrieved from IMG are discussed and compared with the distributions modeled by GEOS-CHEM. The conclusions and perspectives of the study are summarized in Sect. 6 .

\section{CO observations}

A detailed description of the IMG CO observations is given in this section. After a brief presentation of the IMG instrument, the general retrieval method and the characterization procedures are described. Finally, the implementation of the retrieval method for the analysis of the IMG data is described.

\subsection{The IMG instrument}

IMG was a project of the Japanese Ministry of International Trade and Industry (MITI). The mission aimed at measuring the global abundances of the main greenhouse gases from space. The instrument, launched on 17 August 1996 onboard the ADEOS platform, ceased operating at the end of June 1997 after a failure of the satellite. The ADEOS satellite flew on a polar sun synchronous orbit at about $800 \mathrm{~km}$ altitude providing a global Earth coverage from $81^{\circ} \mathrm{N}$ to $81^{\circ} \mathrm{S}$ every 4 days.

IMG is a nadir viewing FTS that measured the radiation emitted by the Earth-atmosphere system. The Maximum Optical Path Difference (MOPD) of the interferometer is $10 \mathrm{~cm}$, leading to a nominal resolution of $0.1 \mathrm{~cm}^{-1}$. The radiation was simultaneously recorded by three detectors to cover the spectral range from 665 to $3030 \mathrm{~cm}^{-1}$. Two photovoltaic InSb detectors covered Band 1, from 2190 to $3030 \mathrm{~cm}^{-1}$ and Band 2, from 1875 to $2500 \mathrm{~cm}^{-1}$, and a photoconductivetype $\mathrm{HgCdTe}$ detector was used for Band 3, from 665 to $2000 \mathrm{~cm}^{-1}$. Each detector had a $0.6^{c}$ irc field of view yielding to a square pixel of $8 \mathrm{~km} \times 8 \mathrm{~km}$ on the Earth's surface. The detector for Band 2, of interest for the CO retrievals, was placed on the optical axis of the interferometer, with the two other detectors on each of its sides.

\subsection{Retrieval methodology}

The CO vertical distributions presented in this paper have been obtained using the Atmosphit software developed at the University Libre de Bruxelles. This software enables the processing of atmospheric FTIR spectra recorded by nadir and solar occultation limb viewing spaceborne instruments and by ground-based instruments (Coheur et al., 2005; Clerbaux et al., 2005; Barret et al., 2005). This section provides a general description of the retrieval process and of the error budget evaluation.

\subsubsection{Forward and inverse model}

For a discretized atmosphere, the analytical relationship between the measured radiance and the true atmospheric state, the forward radiative transfer equation, is given by:

$\boldsymbol{y}=\boldsymbol{F}(\boldsymbol{x} ; \boldsymbol{b})+\epsilon$

where $\boldsymbol{F}$ is the forward radiative transfer model, $\boldsymbol{y}$ is the measurement vector containing the measured radiance, $\boldsymbol{x}$ is the state vector containing the variables to be retrieved (atmospheric concentrations, surface temperature, etc.), $\boldsymbol{b}$ represents all the other fixed parameters having an impact on the measurement (atmospheric temperatures and pressures, instrumental parameters, etc.), and $\epsilon$ is the measurement noise. The radiance that reaches the satellite corresponds to the sum of the radiation emitted by the Earth's surface attenuated by the whole atmosphere, and the radiation emitted by each atmospheric layer attenuated by the atmosphere remaining above it. For each layer, the transmittance spectrum is computed using the line parameters compiled in spectroscopic databases (e.g. HITRAN, Rothman et al., 2003 or GEISA, Jacquinet-Husson et al., 1999) and the absorption continua of water vapor, carbon dioxide, oxygen and nitrogen using the MT-CKD model (Clough et al., 2005). The absorption lines are computed assuming a Voigt line profile. For $\mathrm{CO}_{2}$, 
the lines are modified by chi factors to account for non impact effects as described by Perrin and Hartmann (1989).The integrated radiance that reaches the detector is computed and convolved with the Instrumental Line Shape (ILS).

The goal of the inverse problem is to determine the state vector from the measurement vector. Because some components of the state vector do not contribute to the measurement this is an ill-conditioned problem, meaning that it has no unique solution. Therefore, in order to give a valid solution, the inversion has to be constrained or regularized with an additional source of information. The Optimal Estimation Method (OEM) (Rodgers, 1976, 2000) constrains the inversion with a priori information about the variables to be retrieved. This a priori information, composed of a mean a priori state, $\boldsymbol{x}_{a}$, and an a priori covariance matrix, $\boldsymbol{S}_{a}$, has to represent the best statistical knowledge of the state prior to the measurements. It should therefore be based on a "real" ensemble of states coming from independent sources (e.g. climatology, other observations, atmospheric models).

For a linear problem, the retrieved state, solution of the OEM, is a combination of the measurement and the a priori state inversely weighted by their covariance matrices and is given by (Rodgers, 1976, 2000)

$\hat{\boldsymbol{x}}=\left(\boldsymbol{K}^{T} \boldsymbol{S}_{\epsilon}^{-1} \boldsymbol{K}+\boldsymbol{S}_{a}^{-1}\right)^{-1}\left(\boldsymbol{K}^{T} \boldsymbol{S}_{\epsilon}^{-1} \boldsymbol{y}+\boldsymbol{S}_{a}^{-1} \boldsymbol{x}_{a}\right)$

where $\boldsymbol{S}_{\epsilon}$ is the measurement covariance matrix, and $\boldsymbol{K}=\frac{\partial \boldsymbol{F}}{\partial \boldsymbol{x}}$ is the Jacobian of the forward model. The rows of $\boldsymbol{K}$ are the derivatives of the spectrum with respect to the retrieved variables.

In the case of a non-linear problem, as the retrieval of $\mathrm{CO}$ profiles, the Jacobian is a function of the retrieved state $\hat{\boldsymbol{x}}$ and the solution cannot be directly inferred from Equation 2. An iterative Gauss-Newton method is used instead. At the $i+1$ iteration, the state vector is then given by:

$$
\begin{aligned}
\hat{\boldsymbol{x}}_{i+1}=\boldsymbol{x}_{a}+ & \left(\boldsymbol{K}_{i}^{T} \boldsymbol{S}_{\epsilon}^{-1} \boldsymbol{K}_{i}+\boldsymbol{S}_{a}^{-1}\right)^{-1} \boldsymbol{K}_{i}^{T} \boldsymbol{S}_{\epsilon}^{-1} \\
& {\left[\boldsymbol{y}-\boldsymbol{F}\left(\hat{\boldsymbol{x}}_{i}\right)+\boldsymbol{K}_{i}\left(\hat{\boldsymbol{x}}_{i}-\boldsymbol{x}_{a}\right)\right] }
\end{aligned}
$$

where $\boldsymbol{K}_{i}=\frac{\partial \boldsymbol{F}}{\partial \boldsymbol{x}}\left(\hat{\boldsymbol{x}}_{i}\right)$. The iteration procedure is stopped when the absolute difference between the radiances modeled at the two last iteration steps, $\left|\boldsymbol{F}\left(\hat{\boldsymbol{x}}_{i+1}\right)-\boldsymbol{F}\left(\hat{\boldsymbol{x}}_{i}\right)\right|$, is less than a fraction $(20 \%)$ of the measurement noise. Convergence is generally achieved after less than 5 iterations, and strengthening the convergence criterion does not produce significant changes on the retrieved profiles.

\subsubsection{Characterization of the retrievals}

Since the inverse problem is not strongly non-linear, we can use the linear approximation for the characterization of the retrievals (Rodgers, 1990, 2000). For a linear retrieval, the retrieved state can be written as:

$\hat{\boldsymbol{x}}=\boldsymbol{x}_{a}+\boldsymbol{A}\left(\boldsymbol{x}-\boldsymbol{x}_{a}\right)+\boldsymbol{G}\left(\boldsymbol{\epsilon}+\boldsymbol{K}_{b}(\boldsymbol{b}-\hat{\boldsymbol{b}})\right)$ where $\hat{\boldsymbol{b}}$ is the approximate of the model parameters available to the user. The Jacobian, $\boldsymbol{K}_{b}=\frac{\partial \boldsymbol{F}}{\partial \boldsymbol{b}}$, characterizes the sensitivity of the forward model $\boldsymbol{F}$ to the model parameters. The gain matrix, $\boldsymbol{G}$, is the matrix whose rows are the derivatives of the retrieved state with respect to the spectral points. It is defined by:

$\boldsymbol{G}=\frac{\partial \hat{\boldsymbol{x}}}{\partial \boldsymbol{y}}=\left(\boldsymbol{K}^{T} \boldsymbol{S}_{\epsilon}^{-1} \boldsymbol{K}+\boldsymbol{S}_{a}^{-1}\right)^{-1} \boldsymbol{K}^{T} \boldsymbol{S}_{\epsilon}^{-1}$

The averaging kernel matrix, $\boldsymbol{A}$, sensitivity of the retrieved state to the true state, is the product of the gain matrix by the Jacobian matrix:

$\boldsymbol{A}=\frac{\partial \hat{\boldsymbol{x}}}{\partial \boldsymbol{x}}=\boldsymbol{G} \boldsymbol{K}$

The element $\boldsymbol{A}(i, j)$ is the relative contribution of the element $\boldsymbol{x}(j)$ of the true state to the element $\hat{\boldsymbol{x}}(i)$ of the retrieved state. The vertical resolution of the retrieved profile can be defined as the Full Width at Half Maximum (FWHM) of the rows of the averaging kernel matrix. The number of independent elements of information contained in the measurement can also be estimated as the Degrees Of Freedom for Signal (DOFS) defined as the trace of the averaging kernel matrix (Rodgers, 2000). The averaging kernels are provided for each retrieval enabling an optimal utilisation of the data.

\subsubsection{Error analysis}

In the linear approximation, the total error is computed from the linear retrieval equation (Eq. 4) as the difference between the true state and the retrieved state:

$\hat{\boldsymbol{x}}-\boldsymbol{x}=(\boldsymbol{A}-\boldsymbol{I})\left(\boldsymbol{x}-\boldsymbol{x}_{a}\right)+\boldsymbol{G} \boldsymbol{\epsilon}+\boldsymbol{G} \boldsymbol{K}_{b}(\boldsymbol{b}-\hat{\boldsymbol{b}})$

It can be decomposed in three terms:

1. The smoothing error, $(\boldsymbol{A}-\boldsymbol{I})\left(\boldsymbol{x}-\boldsymbol{x}_{a}\right)$, accounts for the smoothing of the true state by the averaging kernels. The covariance matrix of the smoothing error is given by:

$$
\boldsymbol{S}_{s}=(\boldsymbol{A}-\boldsymbol{I}) \boldsymbol{S}_{a}(\boldsymbol{A}-\boldsymbol{I})^{T}
$$

2. The measurement error, $\boldsymbol{G} \epsilon$, is due to the instrumental noise. Its covariance matrix is given by:

$$
\boldsymbol{S}_{m}=\boldsymbol{G} \boldsymbol{S}_{\epsilon} \boldsymbol{G}^{T}
$$

3. The model parameters error, $\boldsymbol{G} \boldsymbol{K}_{b}(\boldsymbol{b}-\hat{\boldsymbol{b}})$, is accounting for the imperfect knowledge of the model parameters. The covariance of this error term is given by:

$$
\boldsymbol{S}_{p}=\boldsymbol{G} \boldsymbol{K}_{b} \boldsymbol{S}_{b}\left(\boldsymbol{G} \boldsymbol{K}_{b}\right)^{T}
$$

Where $\boldsymbol{S}_{b}$ is the covariance matrix representing the uncertainty on the forward model parameters.

The total error covariance matrix is then given by:

$$
\boldsymbol{S}_{T}=\boldsymbol{S}_{s}+\boldsymbol{S}_{m}+\boldsymbol{S}_{p}
$$




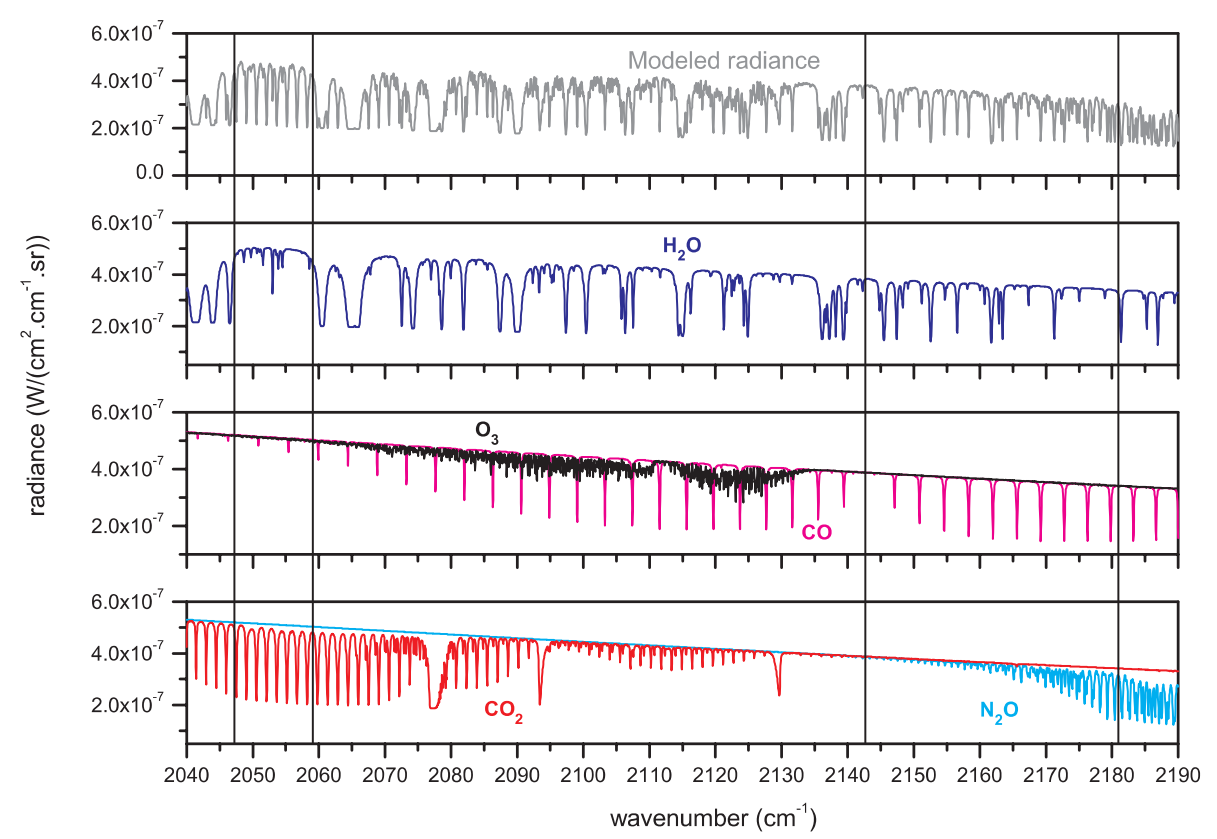

Fig. 1. Simulated IMG radiance for the $2040-2190 \mathrm{~cm}^{-1}$ spectral range (top panel). The contributions of the main absorbers in this spectral range are provided in the three bottom panels. The spectral windows selected for the apodisation parameter retrieval $\left(2047-2059 \mathrm{~cm}^{-1}\right)$ and for the CO profile retrieval $\left(2143-2181 \mathrm{~cm}^{-1}\right)$ are indicated with the vertical lines.

2.3 Application to the retrieval of CO from the IMG measurements

In the previous section, we have provided a general presentation of the retrieval algorithm and of the characterization formalism. The present section describes their implementation for the retrieval of CO profiles from the IMG spectra.

\subsubsection{Selection of spectra}

The Atmosphit software does not account for clouds in its radiative transfer calculations. As a consequence, reliable $\mathrm{CO}$ retrievals can only be obtained from cloud free pixels. We therefore applied the method developed by Hadji-Lazaro et al. (2001) to remove the cloud-contaminated pixels in the IMG Band 2.

Furthermore, for some spectra, especially those recorded over cold surfaces, the signal is very low and some of the $\mathrm{CO}$ absorption lines are not distinguishable from the spectral noise. The selection criterion used to eliminate those spectra is based on the ratio of the absorption depth of the strong (10) R(3) vibration-rotation CO line relative to the noise RMS. All the spectra with an 'absorption to noise ratio' lower than 10 have been filtered out.

\subsubsection{Instrumental Line Shape}

The ILS for the IMG band 2 spectra is modeled taking the nominal $10 \mathrm{~cm}$ MOPD and the $0.6^{\circ}$ straight FOV into account. In order to account for departures from the nom- inal ILS, an apodisation function has been introduced as $\exp \left[-(a x)^{2}\right]$, where $a$ is the apodisation parameter and $x$ is the optical path difference. For each individual spectrum, the parameter $a$ is retrieved from the $\mathrm{CO}_{2}$ lines in the $2047-2059 \mathrm{~cm}^{-1}$ spectral window (Fig. 1). The average retrieved $a$ parameter is 0.14 , meaning a modulation efficiency of $15 \%$ at MOPD. We used the retrieval error on the $a$ parameter $(<5 \%)$ to estimate the uncertainty on the ILS in order to compute the error induced on the $\mathrm{CO}$ retrieved profiles (Eq. 10).

\subsubsection{Choice of the spectral window}

The spectral domain of IMG Band 2 includes the (1-0) vibration-rotation band of carbon monoxide at $4.7 \mu \mathrm{m}$. The strongest absorption lines of this band are spread from 2050 to $2230 \mathrm{~cm}^{-1}$. Figure 1 represents a simulated IMG radiance spectrum for the $2040-2190 \mathrm{~cm}^{-1}$ spectral domain, corresponding to tropical atmospheric conditions, together with the individual contributions of the strongest absorbers in this domain: $\mathrm{H}_{2} \mathrm{O}, \mathrm{CO}, \mathrm{O}_{3}, \mathrm{~N}_{2} \mathrm{O}$, and $\mathrm{CO}_{2}$. Water vapor absorbs all over the domain and its contribution cannot be avoided. The $\mathrm{O}_{3}$ signature extends from 2060 to $2135 \mathrm{~cm}^{-1}$ while $\mathrm{N}_{2} \mathrm{O}$ saturates the signal above $2180 \mathrm{~cm}^{-1}$. In order to minimize the interferences from these species, we have selected the CO retrieval window from 2143 to $2181 \mathrm{~cm}^{-1}$. 


\subsubsection{Retrieval parameters}

The a priori state vector and covariance matrix and the measurement covariance matrix (Sect. 2.2) are parameters that have a strong impact on the retrievals. The a priori state vector and the a priori covariance matrix have been built based on data from the GEOS-CHEM 3D CTM (Sect. 3). The a priori profile used for the selected IMG period analyzed here (1-10 April, 1997), is a monthly average profile generated using April 1997 GEOS-CHEM profiles simulated with a $2^{\circ}$ latitude by $2.5^{\circ}$ longitude grid and a $12 \mathrm{~h}$ time step. The a priori covariance matrix was generated from the same GEOSCHEM dataset and therefore represents the monthly global CO variability for the month of April 1997. The CO mixing ratios are retrieved on 13 vertical levels from the ground up to $31 \mathrm{~km}$. The a priori mixing ratio profile together with the a priori variability are shown in Fig. 2.

We assumed an uncorrelated white noise for the spectrum so that $\boldsymbol{S}_{\epsilon}=\sigma^{2} \boldsymbol{I}$, where $\sigma$ is the noise equivalent spectral radiance (NESR). The NESR of the IMG instrument has been estimated to be of the order of $2 \times 10^{-9} \mathrm{~W} /\left(\mathrm{cm}^{2} \mathrm{~cm}^{-1} \mathrm{sr}\right)$ (Kobayashi et al., 1999). Nevertheless, an analysis of the Root Mean Squares (RMS) of the differences between the measured and the fitted spectra revealed strong variations in the level of noise, with a positive correlation between the signal and the noise levels. The average RMS varies from $5 \times 10^{-9} \mathrm{~W} /\left(\mathrm{cm}^{2} \mathrm{~cm}^{-1} \mathrm{sr}\right)$ in the tropical latitudes where the signal is the highest, to $2.5 \times 10^{-9} \mathrm{~W} /\left(\mathrm{cm}^{2} \mathrm{~cm}^{-1} \mathrm{sr}\right)$ in the subpolar latitudes where the signal is the lowest. In order to constrain the $\mathrm{CO}$ retrievals accordingly, for each individual spectrum, $\sigma$ has been set to the RMS value obtained from the ILS window fit (Sect. 2.3.2).

The surface temperature, the water vapor profile and the $\mathrm{N}_{2} \mathrm{O}$ total column were retrieved simultaneously with the $\mathrm{CO}$ profile.

The spectroscopic parameters have been taken from the HITRAN 2000 compilation (Rothman et al., 2003). For each retrieval, the atmospheric temperature and pressure profiles have been extracted from the European Center for Mediumrange Weather Forecast (ECMWF). We have considered an uncertainty of $2 \mathrm{~K}$ on the atmospheric temperature at each altitude to compute the corresponding error on the retrieved CO profiles (Eq. 10).

\section{The GEOS-CHEM model}

The GEOS-CHEM model (http://www-as.harvard.edu/ chemistry/trop/geos/) (Bey et al., 2001a; Martin et al., 2003; Auvray and Bey, 2005) is a global 3-D CTM driven by assimilated meteorological observations provided by the Goddard Earth Observing System (GEOS) of the NASA Global Modeling and Assimilation Office (GMAO). We used here the version 5-02 of the GEOS-CHEM model with some improvements described in Auvray and Bey (2005).

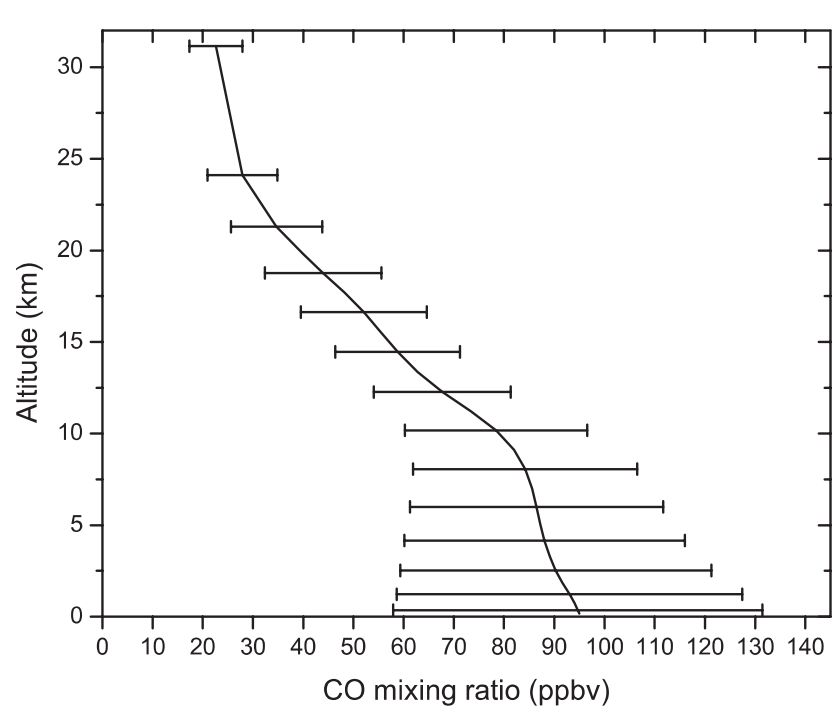

Fig. 2. CO a priori profile and associated vertical variability (square root of the diagonal elements of the a priori covariance matrix).

For the year 1997, we used the GEOS-STRAT version of the GMAO meteorological fields, with a horizontal resolution of $2^{\circ}$ of latitude by $2.5^{\circ}$ of longitude, and 26 vertical sigma levels (from the surface up to $0.01 \mathrm{mbar}$ ). The model includes 80 species and over 300 reactions for a detailed description of the ozone- $\mathrm{NO}_{\mathrm{x}}$-hydrocarbon chemistry. Photolysis frequencies in the troposphere are calculated with the Fast-J algorithm of Wild (2000) which accounts for aerosols and clouds. Heterogeneous reactions on aerosol (sulfate, black carbon, organic carbon, sea salt and dusts) are included, following recommendations from Jacob (2000). The aerosols fields are provided by the Global Ozone Chemistry Aerosol Radiation and Transport (GOCART) model (Chin et al., 2002) and are coupled to the GEOS-CHEM model as described by Martin et al. (2003). The standard CO emission inventories in the GEOS-CHEM model are described in Wang et al. (1998). The year-to-year variability of anthropogenic emissions is taken into account by scaling the base emission inventory for 1985 by specific factors as described in Bey et al. (2001a). In addition, we used here the European Monitoring and Evaluation Program (EMEP) database inventory over Europe for the year 1997 as described in Auvray and Bey (2005). Biomass burning emissions are from a climatological inventory described by Wang et al. (1998). The biomass burning inventory is prescribed specifically to 1997 by using a combination of products from Total Ozone Mapping Spectrometer (TOMS) Aerosol Index (AI) and Along Track Scanning Radiometer (ATSR) fire-counts following Duncan et al. (2003). 
(a)

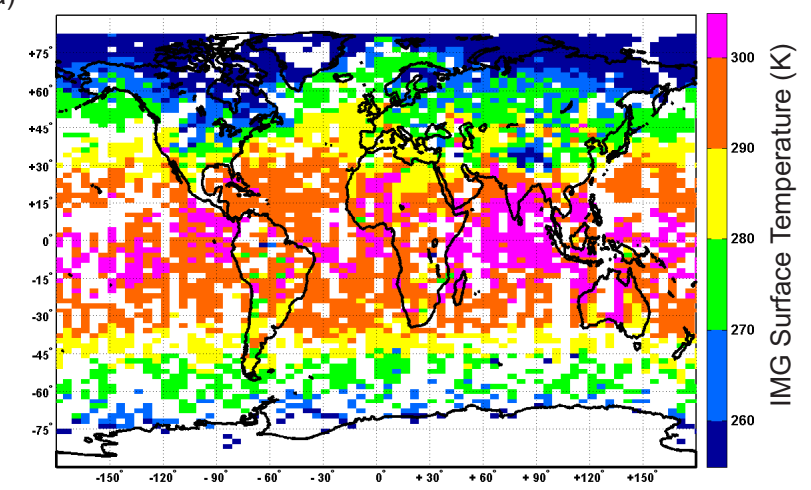

(b)

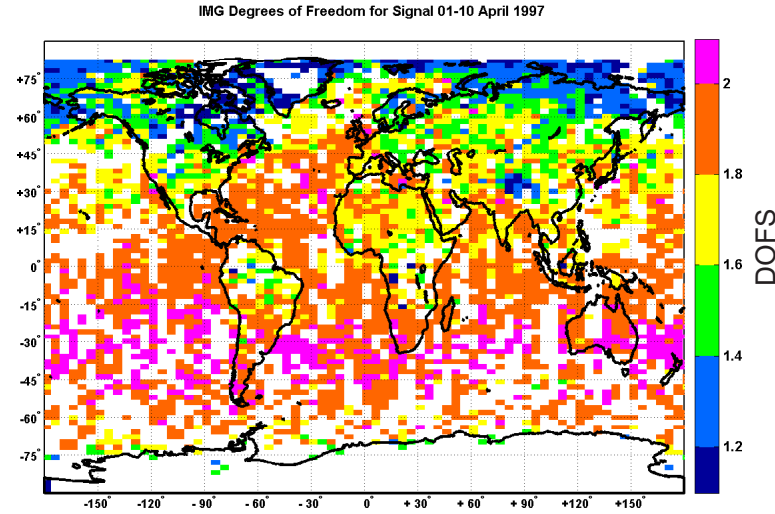

Fig. 3. (a) Surface temperatures retrieved from the cloud filtered IMG spectra for 1-10 April 1997 and (b) corresponding DOFS (averages on a $2^{\circ} \times 5^{\circ}$ grid)

\section{Results and discussion}

This section provides detailed presentation and discussion of the IMG CO retrievals. The retrievals are first characterized in terms of information content and error budget. The $\mathrm{CO}$ lower tropospheric concentrations and total columns are then compared with independent measurements provided by the National Oceanic and Atmospheric Administration (NOAA) Climate Monitoring and Diagnostics Laboratory (CMDL) network and by the Network for Detection of Stratospheric Changes (NDSC) respectively. The global distributions of $\mathrm{CO}$ are finally presented and discussed with the support of simulations by the GEOS-CHEM model.

\subsection{Information content and error analyses}

Figure 3 shows the global distribution of surface temperature and DOFS mean values, for the 1-10 April 1997 period, computed on a $2^{\circ}$ latitude by $5^{\circ}$ longitude grid. The DOFS has a strong latitudinal dependence, as a result of surface temperature variations (Fig. 3a). In the tropics, high surface temperatures result in high signals detected by the instrument and in high DOFS. In the same way, the low surface temperature in the polar regions are responsible for low DOFS.

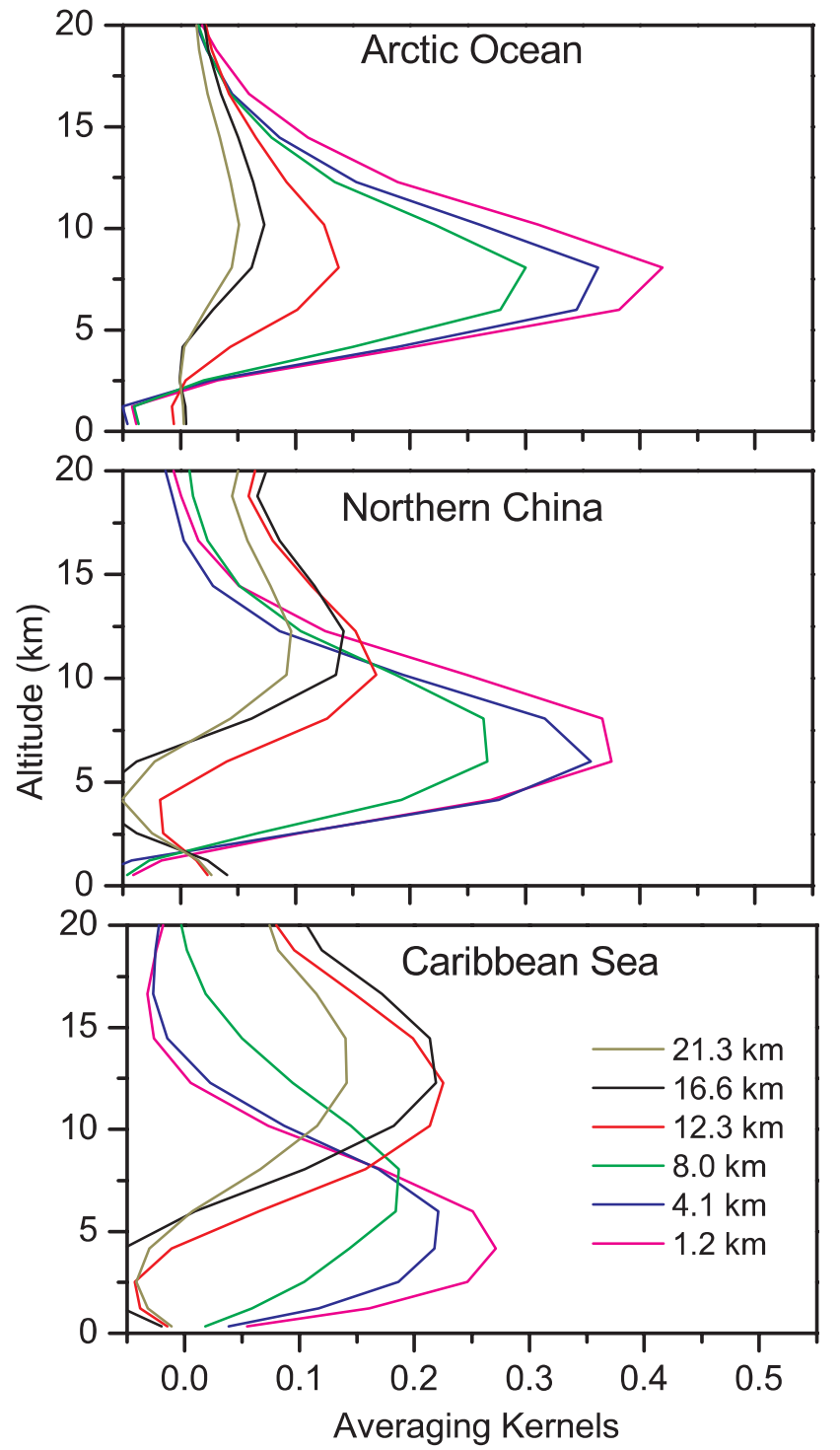

Fig. 4. IMG CO averaging kernels for three selected pixels: Arctic Ocean $\left(75.6^{\circ} \mathrm{N}, 115.2^{\circ} \mathrm{E}\right.$, upper panel), Northern China $\left(45.6^{\circ} \mathrm{N}\right.$, $121.4^{\circ} \mathrm{E}$, middle panel) and Caribbean Sea $\left(14.0^{\circ} \mathrm{N}, 71.5^{\circ} \mathrm{W}\right.$, lower panel).

Furthermore, the occurence of temperature inversion in the lower troposphere, frequent at high latitudes, is responsible of an even lower DOFS and is hindering from detecting CO in the lower troposphere. The pixels measured above $75^{\circ} \mathrm{N}$ and $75^{\circ} \mathrm{S}$ are therefore rejected from our study. In between these limits, the DOFS exceeds 1.5 for more than $75 \%$ of the measurements. In the Northern midlatitudes, the DOFS are also lower over cold land than over warmer oceans. The highest DOFS are found between $15^{\circ} \mathrm{S}$ and $45^{\circ} \mathrm{S}$ as the result of the combination of a warm surface temperature and a low noise RMS. Over mountainous regions, DOFS are especially low because of low surface temperatures and high surface altitudes. 
Three spectra corresponding to a low $(\mathrm{DOFS}=1.2)$, a medium (DOFS=1.6) and a high (DOFS=2.0) information content have been selected for a detailed characterization. They have been recorded over the Arctic Ocean, Northern China and the Caribbean Sea respectively. Figure 4 shows the averaging kernels for each of these three spectra. In the case of the Arctic Ocean, the measurement only allows to retrieve a single piece of information about the $\mathrm{CO}$ vertical distribution, covering the middle-upper troposphere. Over Northern China, it is almost possible to separate the CO content in the middle troposphere and in the upper tropospherelower stratosphere (UTLS). Finally, over the Caribbean Sea, the IMG measurement allows to retrieve independently the $\mathrm{CO}$ content in the lower-middle troposphere and in the upper troposphere.

The amount of information contained in the IMG measurements with regard to the $\mathrm{CO}$ vertical distribution is unprecedented and will not be achieved in the near future. Indeed, according to Deeter et al. (2004), the DOFS obtained by the MOPITT instrument does not exceed 1.7 and 1.5 for its first and second phase of operation, respectively. AIRS is providing $\mathrm{CO}$ profiles with 0.5 to 1.5 DOFS (McMillan et al., 2005). Preparatory studies have reported a DOFS in the range of 0.5 to 0.9 for TES spectrometer (Worden et al., 2004) and of 1.5 for the IASI instrument (Turquety et al., 2004). Preliminary results have shown that it is possible to retrieve about 1 piece of information from TES CO measurements (Ming Luo, private communication). The lower information content about the $\mathrm{CO}$ vertical distribution relative to what is reported here for IMG, is attributable to a higher NESR $\left(>10^{-8} \mathrm{~W} /\left(\mathrm{cm}^{2} \mathrm{~cm}^{-1} \mathrm{sr}\right)\right)$ in the case of TES (Worden et al., 2004) and to a lower spectral resolution (0.35 to $0.5 \mathrm{~cm}^{-1}$ ) in the case of IASI (Turquety et al., 2004).

The vertical profiles for the different errors together with the vertical profile of the a priori variability are displayed in Fig. 5. They correspond to the square root of the diagonal elements of the error covariance matrices calculated according to Eq. (8) to (11) and of the a priori covariance matrix respectively. In the three cases the dominant error at all altitudes is the smoothing error. The three other contributing errors are the measurement error and the errors uncertainties on the air temperature and on the ILS. The two latter terms contribute mainly below and above $10 \mathrm{~km}$, respectively. Errors caused by the simultaneous retrievals of the surface temperature, $\mathrm{H}_{2} \mathrm{O}$ and $\mathrm{N}_{2} \mathrm{O}$ are not shown as they do not provide a significant contribution to the total error. As could be anticipated from the information content analysis, and due to the fact that the smoothing error is dominating all the other errors, the total error is the highest in the Arctic Ocean case and the lowest in the Carribean Sea case. While the total error is substantially lower than the a priori variability over the whole altitude range in the Carribean Sea case, the reduction of uncertainty about the $\mathrm{CO}$ vertical distribution is not significant above $15 \mathrm{~km}$ for both the Arctic Ocean and the Northern China cases.

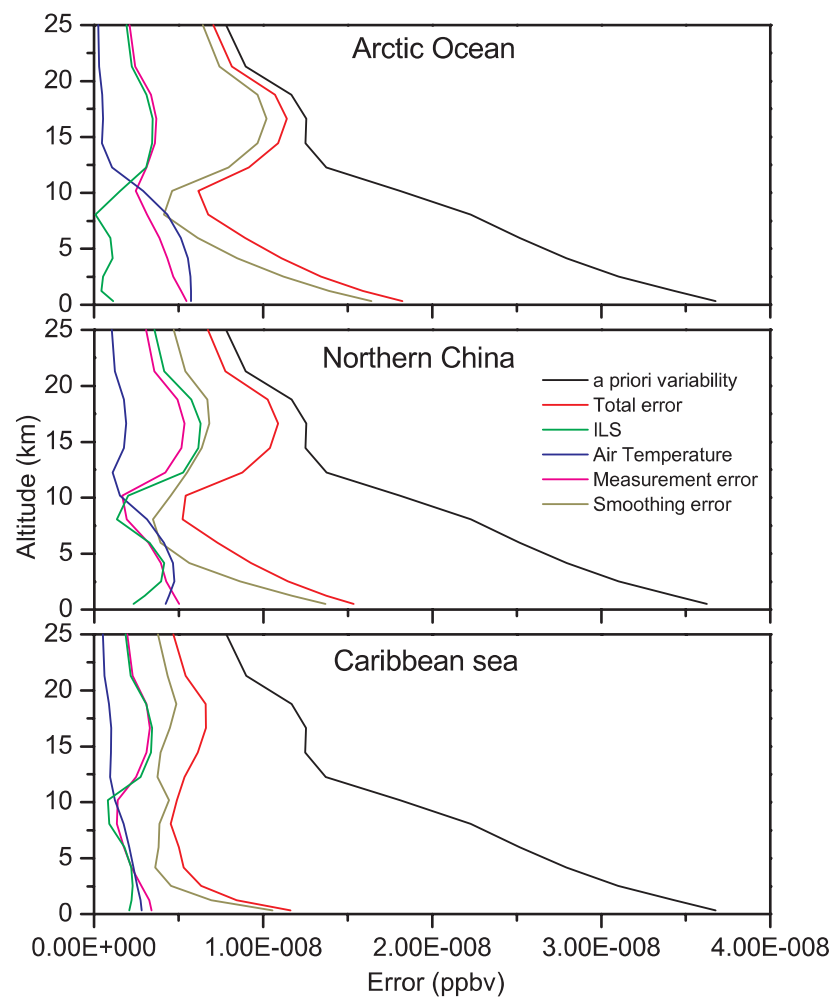

Fig. 5. Same as Fig. 4 for the IMG CO error profiles.

\subsection{Comparisons with independent measurements}

The lack of data about the vertical distribution of $\mathrm{CO}$ for the time period studied prevented us from validating the $\mathrm{CO}$ profiles retrieved from IMG. However, in situ and remote sensing observations made at the ground could be used for a partial validation.

\subsubsection{Comparisons with the NOAA-CMDL measurements}

For decades, routine in situ measurements of the surface $\mathrm{CO}$ mixing ratios have been provided worldwide by the NOAA/CMDL network (Novelli et al., 1992, 1998). The results of the comparison between the IMG lower tropospheric $\mathrm{CO}$ mixing ratios (at $1.2 \mathrm{~km}$ ) and the mixing ratios measured in situ at the CMDL network stations are given in Table 1 and can be visualized in Fig. 6. In the Northern Hemisphere, where the $\mathrm{CO}$ spatial and temporal variabilities are high, the IMG CO mixing ratio is calculated as the average over all observations lying within 6 longitude and 3 latitude from the location of the CMDL station and measured either the same day, the day before or the day after the in situ measurements. In the Southern Hemisphere, the CO variability is much lower. Therefore, the spatial coincidence criteria has been relaxed to 9 longitude and 4.5 latitude and the temporal coincidence has been extended to one more day before and after the in situ observation. In all cases, the altitude 


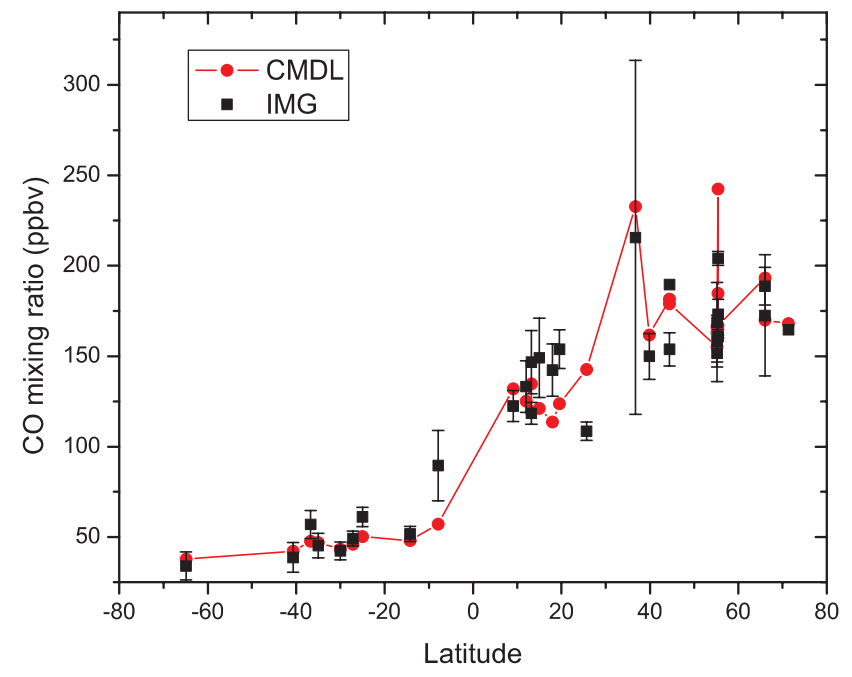

Fig. 6. Comparison between the $\mathrm{CO}$ mixing ratios measured in situ at the surface by the CMDL, and the coincident IMG lower tropospheric CO mixing ratios for 1-10 April 1997.

of the scene overlooked by IMG must be within $250 \mathrm{~m}$ from the altitude of the CMDL station. Furthermore, in order to select measurements that contain useful information about the $\mathrm{CO}$ content in the altitude range of interest, we used the "percent a priori" diagnostic described in Kar et al. (2004) to filter the MOPITT data. Spectra were selected such that the ratio of the inversion error (sum of the smoothing and measurement errors) to the a priori variability, or "percent ratio", doesn't exceed 0.5. A "percent ratio" tending to 0 actually indicates a perfect retrieval, whereas a value close to 1 reveals a measurement containing no useful information. For the IMG period 1-10 April 1997, we found 30 coupled observations fulfilling the coincidence criteria.

The calculated mean relative difference between both datasets is less than $1 \%$ and the relative standard deviation of the differences is $14 \%$. This indicates that no significant bias exists between the IMG and the CMDL observations. Furthermore, the relative standard deviation of the CMDL values $(47 \%)$ is 3.4 times higher than the relative standard deviations of the differences, clearly indicating that IMG brought valuable information about the lower tropospheric $\mathrm{CO}$ content. This is confirmed by a very high correlation coefficient ( $R=0.96$ ) between both datasets. The excellent agreement can be surprising considering the low sensitivity of IMG to the boundary layer. It can be explained by the strong correlation that bounds $\mathrm{CO}$ in the lower-middle troposphere -to which IMG is sensitive- and the surface $\mathrm{CO}$ measured at the CMDL stations. For the same reason, Clerbaux et al. (2001) showed that the assimilation of IMG CO total columns into the 3-D CTM MOZART consistently improved the agreement between the model and the CMDL observations.
Table 1. $\mathrm{CO}$ surface mixing ratios measured at the NOAA/CMDL network stations and lower tropospheric $\mathrm{CO}$ mixing ratios retrieved from coincident IMG measurements.

\begin{tabular}{|c|c|c|c|c|}
\hline \multirow[t]{2}{*}{ Station } & \multirow[t]{2}{*}{ Latitude } & \multirow[t]{2}{*}{ Longitude } & CMDL & IMG \\
\hline & & & \multicolumn{2}{|c|}{ ppbv } \\
\hline PSA & -64.92 & -64.00 & 38 & $34 \pm 8$ \\
\hline CGO & -40.68 & 144.68 & 42 & $39 \pm 8$ \\
\hline OPB & -36.72 & 159.92 & 48 & $57 \pm 8$ \\
\hline OPC & -35.00 & 176.03 & 47 & $45 \pm 7$ \\
\hline OPC & -30.00 & 179.50 & 43 & $42 \pm 5$ \\
\hline EIC & -27.15 & -109.45 & 46 & $49 \pm 4$ \\
\hline OPC & -25.00 & -177.17 & 50 & $61 \pm 5$ \\
\hline SMO & -14.25 & -170.57 & 48 & $52 \pm 4$ \\
\hline ASC & -7.92 & -14.42 & 57 & $89 \pm 19$ \\
\hline SCS & 9.05 & 109.40 & 132 & $122 \pm 8$ \\
\hline SCS & 11.98 & 111.08 & 125 & $133 \pm 14$ \\
\hline RPB & 13.17 & -59.43 & 135 & $147 \pm 17$ \\
\hline RPB & 13.17 & -59.43 & 119 & $118 \pm 6$ \\
\hline SCS & 15.00 & 112.62 & 121 & $149 \pm 22$ \\
\hline SCS & 18.00 & 114.17 & 114 & $142 \pm 14$ \\
\hline KUM & 19.52 & -154.82 & 124 & $154 \pm 11$ \\
\hline KEY & 25.67 & -80.20 & 143 & $108 \pm 5$ \\
\hline TAP & 36.73 & 126.13 & 233 & $216 \pm 98$ \\
\hline UTA & 39.90 & -113.72 & 162 & $150 \pm 13$ \\
\hline UUM & 44.45 & 111.10 & 179 & 189 \\
\hline UUM & 44.45 & 111.10 & 181 & $154 \pm 9$ \\
\hline CBA & 55.20 & -162.72 & 163 & $169 \pm 22$ \\
\hline CBA & 55.20 & -162.72 & 166 & $158 \pm 14$ \\
\hline CBA & 55.20 & -162.72 & 155 & $151 \pm 15$ \\
\hline BAL & 55.43 & 16.95 & 242 & $204 \pm 4$ \\
\hline BAL & 55.43 & 16.95 & 167 & $161 \pm 1$ \\
\hline BAL & 55.43 & 16.95 & 185 & $173 \pm 8$ \\
\hline STM & 66.00 & 2.00 & 193 & $172 \pm 33$ \\
\hline STM & 66.00 & 2.00 & 170 & $189 \pm 10$ \\
\hline BRW & 71.32 & -156.60 & 168 & 164 \\
\hline
\end{tabular}

\subsubsection{Comparisons with the NDSC measurements}

Since the 80's, ground-based FTIR measurements are performed at a number of stations of the NDSC around the globe. Accurate $\mathrm{CO}$ total columns, routinely retrieved from these measurements, have already been used for the validation of spaceborne instruments (Pougatchev et al., 1998; Barret et al., 2003). Unfortunately, most of the NDSC stations are located at high latitudes in the Northern Hemisphere and many of them at high altitude sites. Six stations providing CO measurements between 1 and 10 April 1997, were found collocated with the IMG measurements according to the same spatial coincidence criteria adopted for the comparison of IMG lower tropospheric CO with the CMDL data. The comparison was performed between total columns averaged over the entire 1-10 April period. The results of the comparison are detailed in Table 2 and displayed in Fig. 7. A fair agreement is found between both datasets with a mean 


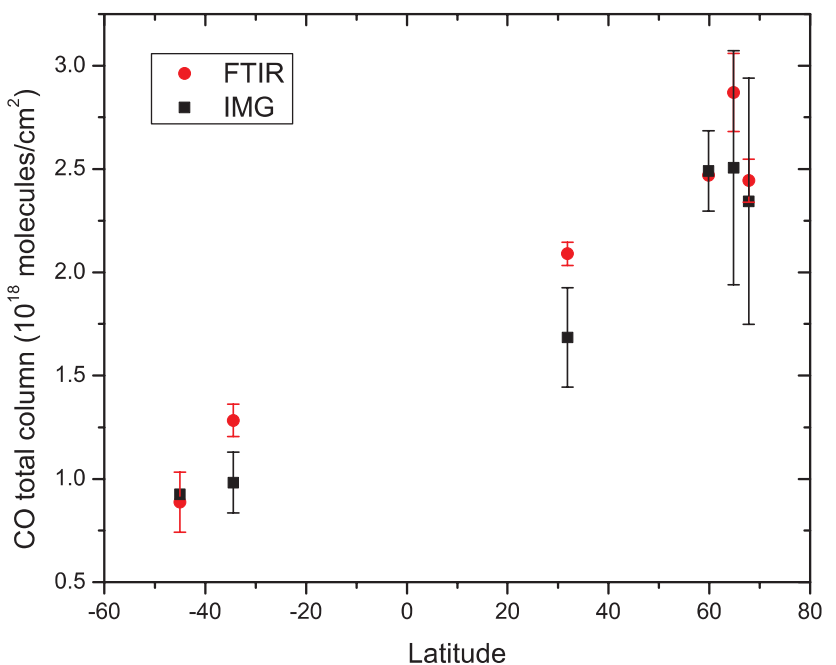

Fig. 7. Comparison between the $\mathrm{CO}$ total columns measured by FTIR ground-based instruments from the NDSC, and the coincident CO total columns retrieved from IMG for 1-10 April 1997.

Table 2. CO total columns measured at the NDSC stations and retrieved from coincident IMG measurements.

\begin{tabular}{|c|c|c|c|c|}
\hline \multirow[t]{2}{*}{ Station } & \multirow[t]{2}{*}{ Latitude } & \multirow[t]{2}{*}{ Longitude } & NDSC & IMG \\
\hline & & & \multicolumn{2}{|c|}{$10^{18}$ molecules $/ \mathrm{cm}^{2}$} \\
\hline Lauder & -45.05 & 169.68 & $0.9 \pm 0.1$ & 0.9 \\
\hline Wollongong & -34.45 & 150.88 & $1.3 \pm 0.1$ & $1.0 \pm 0.1$ \\
\hline Kitt Peak & 31.90 & -111.60 & $2.1 \pm 0.1$ & $1.7 \pm 0.2$ \\
\hline St Petersbourg & 59.88 & 29.83 & 2.5 & $2.5 \pm 0.2$ \\
\hline Fairbanks & 64.83 & -147.61 & $2.9 \pm 0.2$ & $2.5 \pm 0.6$ \\
\hline Kiruna & 67.84 & 20.41 & $2.4 \pm 0.1$ & $2.3 \pm 0.6$ \\
\hline
\end{tabular}

bias of $9 \pm 9 \%$. At the NDSC station of Wollongong, the higher columns measured by the NDSC instrument is probably due to local urban pollution. At the high altitude station of Kitt Peak, the complex topographic situation of the Rocky Mountains may be responsible for the discrepancy between the retrieved IMG columns and the NDSC measurements.

\subsection{Global distributions of $\mathrm{CO}$}

The global distributions of $\mathrm{CO}$ in the lower and upper troposphere and of CO total columns retrieved from the IMG data are presented in this section and compared with the distributions modeled by GEOS-CHEM. In order to make a meaningfull comparison, the high resolution profiles modeled by GEOS-CHEM, $\boldsymbol{x}_{\text {Model }}$, have to be smoothed according to the averaging kernels matrix of the low resolution retrievals according to (Connor et al., 1994; Rodgers, 2000):

$\boldsymbol{x}_{\text {Model Smoothed }}=\boldsymbol{x}_{a}+\boldsymbol{A}\left(\boldsymbol{x}_{\text {Model }}-\boldsymbol{x}_{a}\right)$, (a)

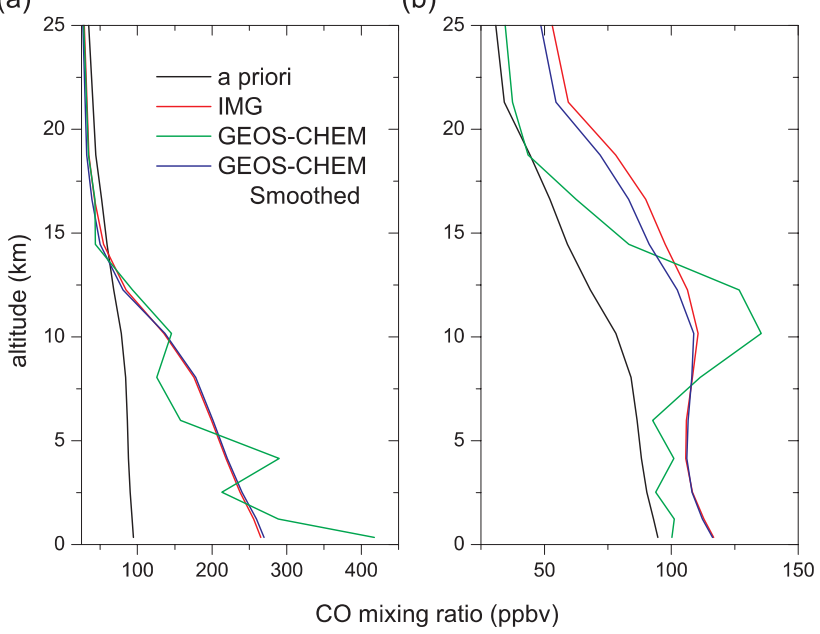

Fig. 8. CO mixing ratios vertical profiles over (a) Northern China $\left(39.8^{\circ} \mathrm{N}, 125.7^{\circ} \mathrm{E}\right)$ and (b) off the coast of Suriname $\left(7.4^{\circ} \mathrm{N}\right.$, $\left.53.4^{\circ} \mathrm{W}\right)$. The black lines show the IMG a priori profile, the red lines show the IMG retrieved profiles, the green lines show the profiles simulated by GEOS-CHEM and the blue lines show the same GEOS-CHEM profiles smoothed by the IMG averaging kernels.

Two cases showing the impact of the smoothing by the averaging kernels on the modeled profiles are shown in Fig. 8. Over polluted Northern China (Fig. 8a), the very high CO mixing ratio in the boundary layer and the secondary $\mathrm{CO}$ maximum in the free troposphere modeled by GEOS-CHEM are smoothed by the measurement, leading in particular to a substantially lower concentration in the lower troposphere. Off the coast of Suriname (Fig. 8b), the upper tropospheric $\mathrm{CO}$ maximum, caused by the convection and advection of polluted air masses, is also smoothed, resulting in a higher $\mathrm{CO}$ concentration in the lower troposphere and in a lower $\mathrm{CO}$ concentration in the upper troposphere at the altitude of the maximum. In both cases, the agreement between the model and the measurement is improved by the smoothing procedure.

\subsubsection{Lower troposphere}

The global distribution of CO lower tropospheric $(1.2 \mathrm{~km})$ mixing ratios retrieved from IMG for the period 1-10 April 1997 is presented in Fig. 9a. As for the IMG/CMDL comparison (Sect. 4.2.1), the 0.5 "percent ratio" criterion was used to select measurements containing useful information.

The major anthropogenic sources of $\mathrm{CO}$ are located in the Northern Hemisphere, over Europe, North America and Asia. This is seen in Fig. 9a which clearly illustrates the strong CO gradient from the Northern to the Southern Hemisphere. High CO concentrations are also observed in Africa and Asia, where vegetation burning during the dry season months (October to March in the Northern Hemisphere) releases high quantities of $\mathrm{CO}$ in the atmosphere. This is 
(a)

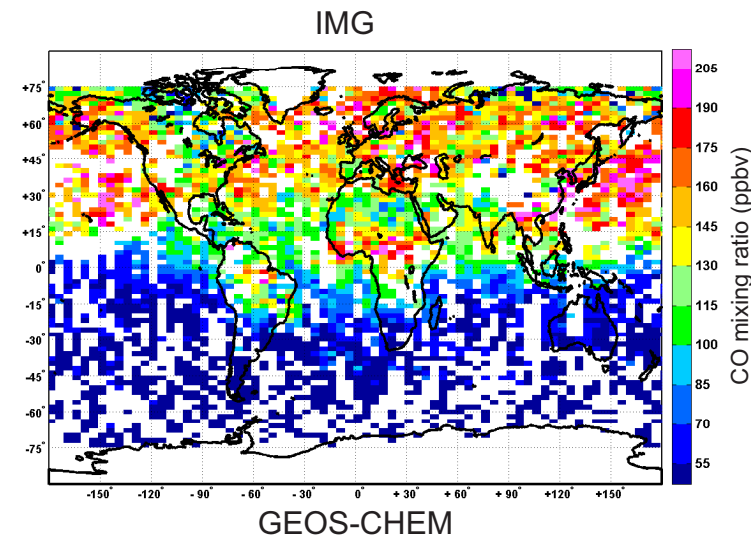

(b)

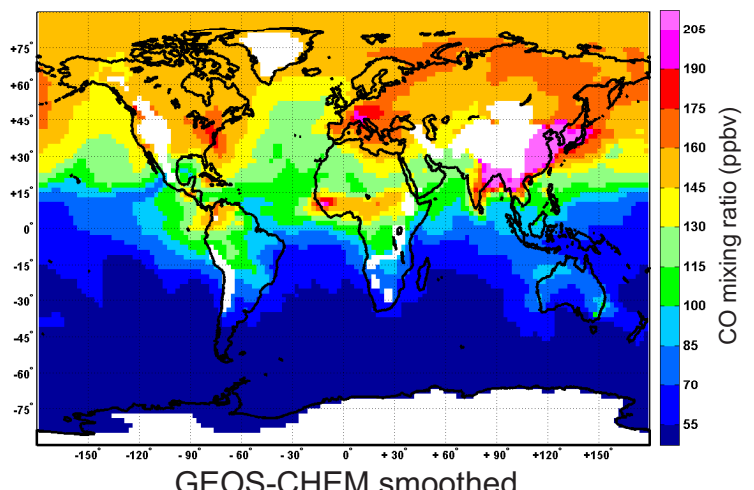

(c)

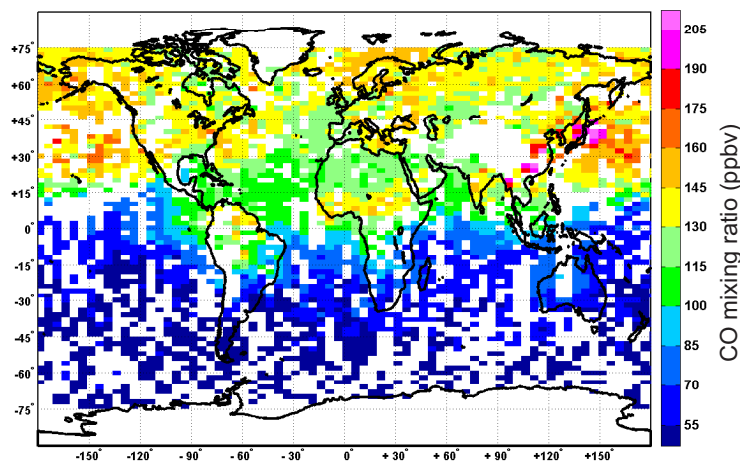

Fig. 9. CO volume mixing ratios (ppbv) in the lower troposphere $(1.2 \mathrm{~km})$ for 1-10 April 1997 (a) retrieved from the cloud filtered IMG spectra (averages on a $2^{\circ} \times 5^{\circ}$ grid), (b) modeled by GEOSCHEM (on the model $2^{\circ} \times 2.5^{\circ}$ grid) and (c) modeled by GEOSCHEM and smoothed by the IMG averaging kernels (averages on a $2^{\circ} \times 5^{\circ}$ grid).

also clearly seen by observations from the Along Track Scanning Radiometer (ATSR, http://shark1.esrin.esa.it/ionia/ FIRE/AF/ATSR/) and shown in Fig. 10. Over Southeast Asia, ATSR detects a higher fire density over the Indochina Peninsula than over the Indian Peninsula in good agreement with the IMG concentrations over India which are lower than those observed over the Indochina Peninsula. The highest IMG concentrations over Brazil do not correspond exactly to the fire locations. This likely results from the smoothing of the $\mathrm{CO}$ profiles, which produces higher $\mathrm{CO}$ concentrations in the lower troposphere as shown in Fig. 8b.

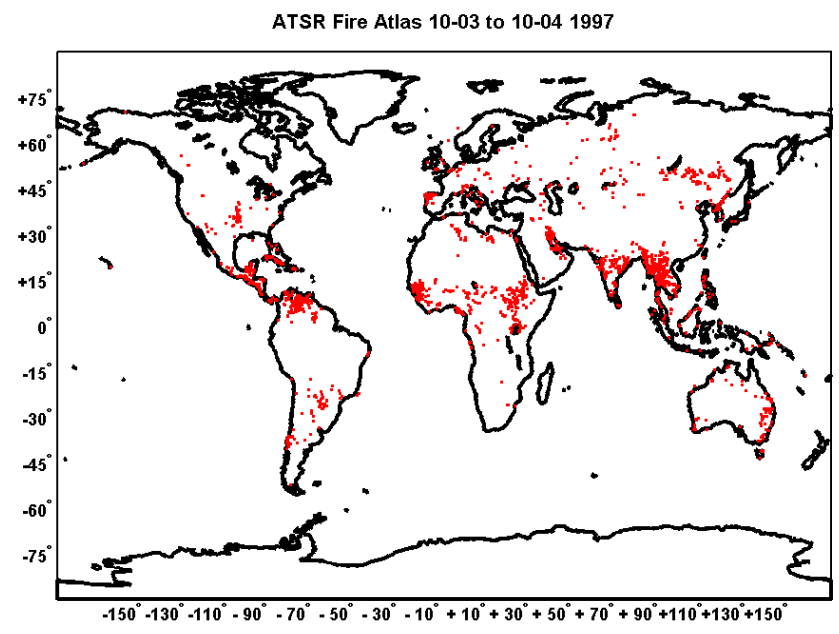

Fig. 10. Data from the ATSR World Fire Atlas for 10 March-10 April 1997.

High CO mixing ratios are also measured by IMG over the Northern Pacific Ocean and the Northern Atlantic Ocean. These observations are consistent with observations provided by several aircraft campaigns dedicated to the sampling of Asian and North American outflow, respectively. In the lower troposphere, elevated concentrations of $\mathrm{CO}$ (up to $250 \mathrm{ppbv}$ ) were frequently recorded off the coast of Asia, especially in spring when the Asian outflow is strongest (Jacob et al., 2003; Russo et al., 2003). Both biomass burning and anthropogenic sources contribute to the Asian outflow at that time of the year (e.g., Bey et al. (2001b)) and thus induce particularly strong concentrations. Concentrations up to $200 \mathrm{ppbv}$ were also observed in spring over the Northern Atlantic (e.g., Cooper et al. (2002b)) where cyclones frequently entrained pollution from the North American boundary layer (Cooper et al., 2002a,b).

Figure $9 \mathrm{~b}$ displays the distribution of the lower tropospheric CO mixing ratios $(1.2 \mathrm{~km})$ averaged over 1-10 April 1997 as simulated by GEOS-CHEM. The model data after convolution by the IMG averaging kernels (Eq. 12) are presented in Fig. 9c. The comparison between Fig. 9b and c clearly shows the impact of the smoothing on the GEOSCHEM data. The smoothing procedure leads to lower (15 to $60 \mathrm{ppbv}$ ) $\mathrm{CO}$ concentrations in the lower troposphere, over highly polluted areas (e.g., Southeast Asia, Africa and China) and to higher ( 15 to $45 \mathrm{ppbv}$ ) $\mathrm{CO}$ concentrations over areas with high $\mathrm{CO}$ concentrations in the middle-upper troposphere (e.g., Northern Pacific and Northern Brazil) as shown in Fig. 8a and b respectively. Once the smoothing is taken into account, the model reproduces the global variations of $\mathrm{CO}$ in the lower troposphere measured by IMG. Both datasets are highly correlated $(R=0.81)$ and the mean global relative difference $(4 \pm 30 \%)$, indicates the absence of a systematic bias between the model and the measurements. However, high CO concentrations measured by IMG 
(a)

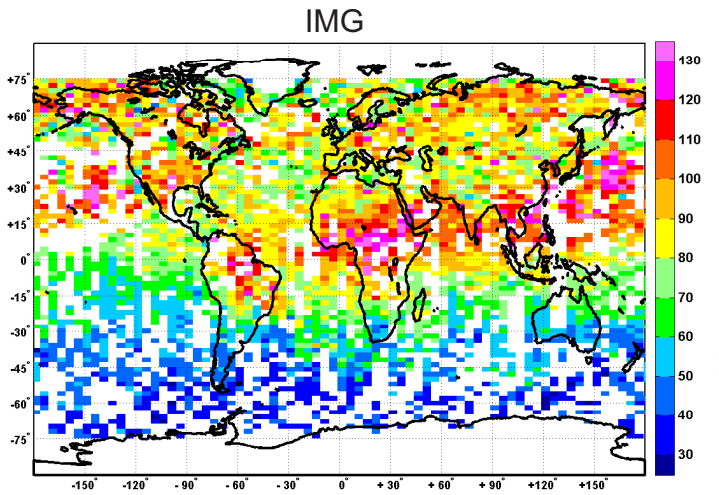

(b)

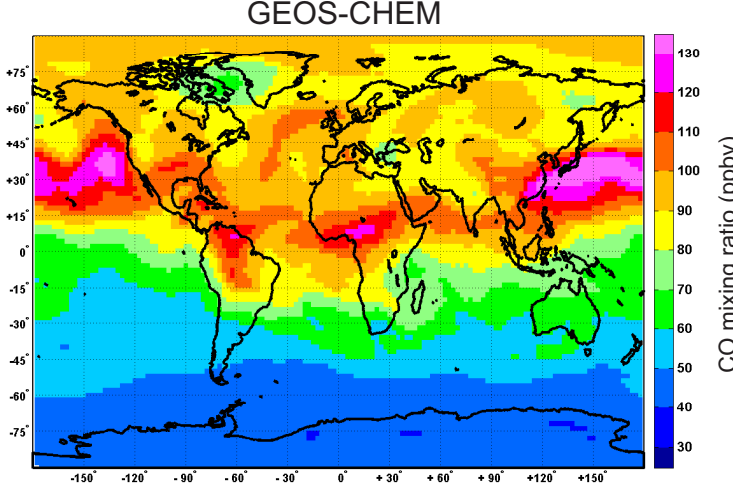

(c)

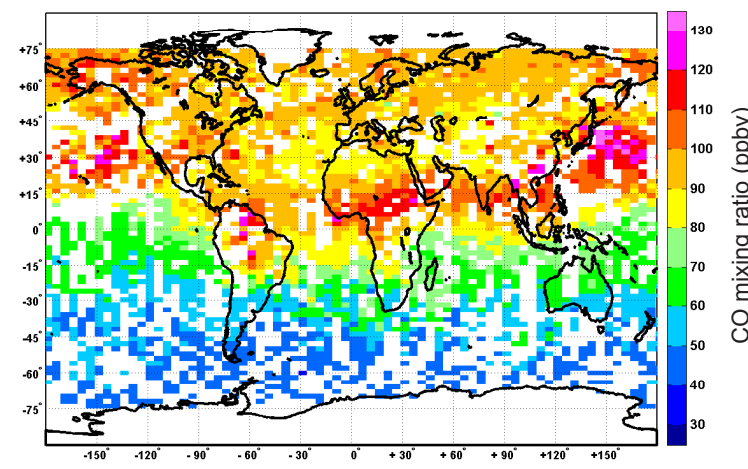

Fig. 11. Same as Fig. 9 for the $\mathrm{CO}$ volume mixing ratios (ppbv) in the upper troposphere $(10.2 \mathrm{~km})$.

in the Northern Hemisphere are underestimated by the model while, on the contrary, the low concentrations measured in the Southern Hemisphere are overestimated. The discrepancy between IMG and GEOS-CHEM over Europe agrees with Auvray and Bey (2005) who report an underestimation of the GEOS-CHEM CO concentrations in winter and spring 1997 by about 20 ppbv relative to NOAA/CMDL observations.

\subsubsection{Upper troposphere}

Figure 11a displays the global distribution of $\mathrm{CO}$ mixing ratios in the upper troposphere (10.2 km) for 1-10 April 1997. The measurements were selected with the same procedure than in the lower troposphere. (a)

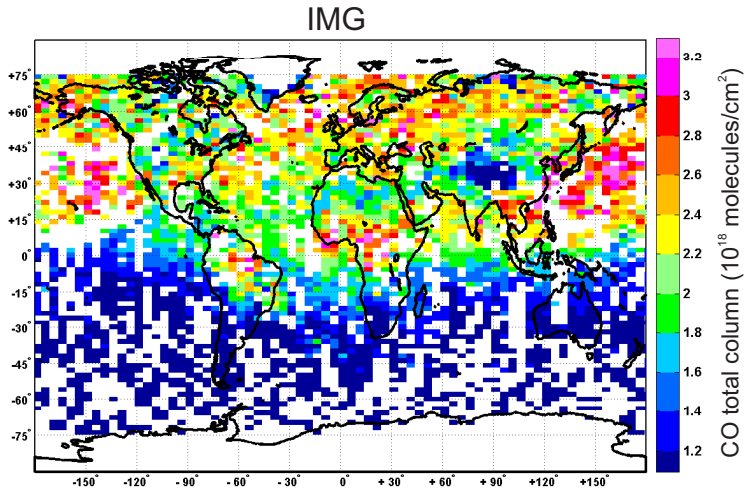

(b)

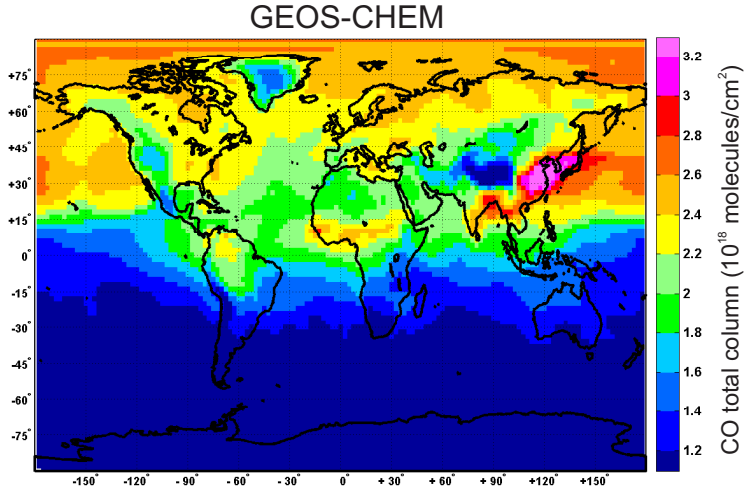

(c)

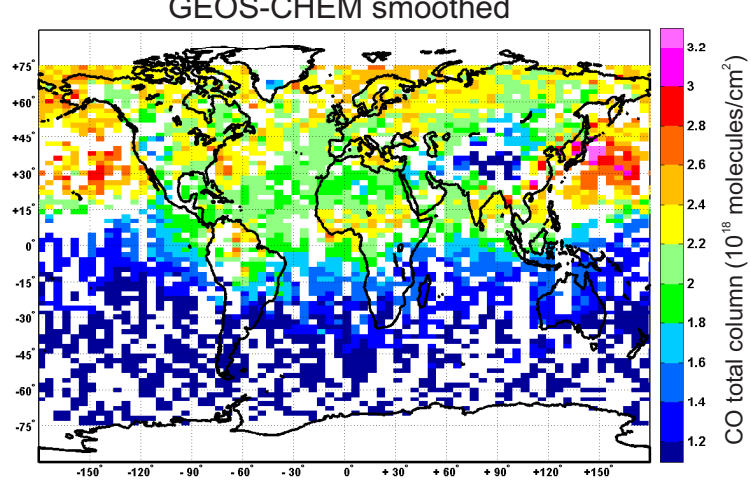

Fig. 12. Same as Fig. 9 for the $\mathrm{CO}$ total columns.

Little is known so far on the global distribution of $\mathrm{CO}$ in the upper troposphere. Elevated $\mathrm{CO}$ concentrations (up to $130 \mathrm{ppbv}$ ) are retrieved from the IMG observations over a large portion of the tropics and over the Northern Pacific. In the tropics, the highest concentrations appear to be collocated with the fires, and thus are likely to result from strong convection that lifts the pollution at higher levels. $\mathrm{CO}$ concentrations are then further entrained over the oceans. For example, strong convective activity over south-eastern Asia have been shown to contribute to the export of pollution to the Northen Pacific (Bey et al., 2001b; Russo et al., 2003). Over the western Pacific in winter-spring, Russo et al. (2003) reported an average $\mathrm{CO}$ mixing ratio in the upper troposphere of 100 to $130 \mathrm{ppbv}$ (with values up to $200 \mathrm{ppbv}$ ), in good agreement with the values retrieved from IMG. 
The upper tropospheric $(10.2 \mathrm{~km}) \mathrm{CO}$ distribution simulated by GEOS-CHEM and averaged over 1-10 April 1997 is shown in Fig. 11b. Figure 11c displays the GEOS-CHEM upper tropospheric mixing ratios after convolution with the IMG averaging kernels. The impact of the smoothing on the model data, less pronounced than in the lower troposphere, reduces the highest $\mathrm{CO}$ concentrations as discussed about Fig. $8 \mathrm{~b}$. The smoothed modeled data agree well with the IMG observations (Fig. 11a). In particular, the elevated CO concentrations measured over the Tropics and the Northern Pacific Ocean are very well reproduced by the model. We calculated a correlation coefficient of 0.75 and a mean difference of $-4 \pm 20 \%$ between both datasets.

\subsubsection{Total columns}

The global distribution of the IMG CO total columns for 110 April 1997 is displayed in Fig. 12a. Because of the sharp decrease of the $\mathrm{CO}$ density with altitude, the total columns are mainly representative of the lower troposphere. A comparison of Fig. 12a and Fig. 9a shows that the distribution of $\mathrm{CO}$ total columns present the same general features as the lower tropospheric $\mathrm{CO}$ distribution. Furthermore, as a result of high altitude, low $\mathrm{CO}$ total columns are retrieved over mountainous regions such as the Himalayan range, the Tibetan Plateau, Greenland or the Rocky Mountains. The same similarity between total columns and lower tropospheric mixing ratios are observed with the model (Fig. 12b) and with the model smoothed by the IMG averaging kernels (Fig. 12c). On the overall, the agreement between the model and the measurements is slightly better for the total columns than for the lower tropospheric mixing ratios (correlation coefficient of 0.82 and relative difference of $1 \pm 22 \%$ ). This is expected as the total column is the quantity which is best retrieved from nadir spectra.

\section{Conclusions}

We have presented vertical profiles of $\mathrm{CO}$ that have been retrieved from spectra provided by a nadir viewing spaceborne FTS for the first time. The retrieval and characterisation algorithms that have been developed in the framework of the IASI mission have been described in details. A thorough characterisation of the retrievals has shown that the high quality radiances measured by the IMG instrument, combining a high signal to noise ratio and a high resolution, enabled to retrieve from 1.5 to 2.2 pieces of information about the $\mathrm{CO}$ vertical profiles over most of the surface of the globe. The lowest information content is found over the cold high latitude or high altitude regions, while over the warm tropical and subtropical regions, about 2 pieces of information are consistently present in the measurements. The first piece of information is located in the lower-middle troposphere and the second one in the UTLS. The error analysis showed that the main source of error is the smoothing error with added contributions from the measurement error and from the errors due to the uncertainties on the temperature profile and on the ILS. In all cases, it was shown that the measurements provide a significant reduction of the a priori uncertainty about the $\mathrm{CO}$ vertical profiles from the surface up to the UTLS.

Comparison of the IMG lower tropospheric $\mathrm{CO}$ mixing ratios with in situ surface observations from the NOAA/CMDL network showed an excellent agreement. A good agreement was also found between $\mathrm{CO}$ total columns retrieved from IMG and measured by FTIR instruments at 6 NDSC stations.

The $\mathrm{CO}$ global distributions of mixing ratios in the lower and in the upper troposphere, and of total columns retrieved from IMG were presented, and compared to distributions modeled by the GEOS-CHEM 3D CTM. A good overall agreement was found between the model and the measurements with correlation coefficients exceeding 0.75 . In the lower troposphere, the model underestimates the high $\mathrm{CO}$ concentrations in the Northern Hemisphere. In the upper troposphere, the model reproduces the high $\mathrm{CO}$ concentrations measured in the Tropics and over the Pacific Ocean.

This work, performed with the IMG data, has proven that the use of the Atmosphit software and its associated characterisation tools will bring a significant contribution to the optimal exploitation of the data that will be collected by the IASI instrument in the coming years. Information about the vertical distribution of $\mathrm{CO}$ will be useful to improve the understanding and the characterisation of tropospheric chemistry and transport. The 3-D view of the $\mathrm{CO}$ distribution enabled by these tools will in particular help to understand the convective processes and the upper tropospheric circulation that take place in the tropical regions.

Acknowledgements. This research was funded by the Fonds National de la Recherche Scientifique (FNRS, Belgium), the Belgian State, Federal Office for Scientific, Technical and Cultural Affairs and the European Space Agency (contracts EV/11/03C and ESA-PRODEX C90-115). Financial support provided by the "Actions de Recherche Concertées" (Communauté française de Belgique) is acknowledged. The development of the retrieval algorithm was undertaken in the framework of the ISSWG (IASI Science Team working group). The authors wish to thank the IMGDIS-ERSDAC for providing the IMG level 1 data. The GEOS-CHEM model is managed by the Atmospheric Chemistry Modeling Group at Harvard University with support from the NASA Atmospheric Chemistry Modeling and Analysis Program. We thank the people responsible for the NDSC and the NOOA/CMDL CO observations for making them available to us on their websites (see http://www.ndsc.ncep.noaa.gov and http://www.cmdl.noaa.gov/infodata). Finally, we aknowledge the people from ATSR World Fire Atlas at the European Space Agency (ESA/ESRIN) for providing us with their data (see http://shark1.esrin.esa.it/ionia/FIRE/AF/ATSR).

Edited by: D. Grainger 


\section{References}

Auvray, M. and Bey, I.: Long-Range Transport to Europe: Seasonal Variations and Implications for the European Ozone Budget, J. Geophys. Res., 110, D11303, doi:10:1029/2004JD005503, 2005.

Barret, B., De Mazière, M., and Mahieu, E.: Ground-based FTIR measurements of $\mathrm{CO}$ from the Jungfraujoch: Characterisation and comparison with in situ surface and MOPITT data, Atmos. Chem. Phys., 3, 2217-2223, 2003,

\section{SRef-ID: 1680-7324/acp/2003-3-2217.}

Barret, B., Hurtmans, D., Carleer, M. R., De Mazière, M., Mahieu, E., and Coheur, P.-F.: Line narrowing effect on the retrieval of $\mathrm{HF}$ and $\mathrm{HCl}$ vertical profiles from ground-based FTIR measurements, J. Quant. Spectrosc. Radiat. Transfer, 95, 499-519, 2005.

Bey, I., Jacob, D. J., Yantosca, R. M., Logan, J. A., Field, B., Fiore, A. M., Li, Q., Liu, H., Mickley, L. J., and Schultz, M.: Global modeling of tropospheric chemistry with assimilated meteorology: Model description and evaluation, J. Geophys. Res., 106, 23 073-23 096, 2001a.

Bey, I., Jacob, D. J., Logan, J. A., and Yantosca, R. M.: Asian chemical outflow to the Pacific in spring: Origins, pathways, and budgets, J. Geophys. Res., 106, 23 097-23 113, 2001 b.

Buchwitz, M., Beek, R., Bramstedt, K., Noël, S., Bovensmann, H., and Burrows, J.: Global carbon monoxide as retrieved from SCIAMACHY by WFM-DOAS, Atmos. Chem. Phys., 4, 19451960, 2004,

\section{SRef-ID: 1680-7324/acp/2004-4-1945.}

Chin, M., Ginoux, P., Kinne, S., Torres, O., Holben, B., Duncan, B. N., Martin, R. V., Logan, J. A., Higurashi, A., and Nakajima, T.: Tropospheric aerosol optical thickness from the GOCART model and comparisons with satellite and sunphotometer measurements, J. Atmos. Sci., 59, 461-483, 2002.

Clerbaux, C., Hadji-Lazaro, J., Hauglustaine, D., Mégie, G., Khattatov, B., and Lamarque, J.-F.: Assimilation of carbon monoxide measured from satellite in a three-dimensional chemistrytransport model, J. Geophys. Res., 106, 15 385-15 394, 2001.

Clerbaux, C., Hadji-Lazaro, J., Turquety, S., Mégie, G., and Coheur, P.-F.: Trace gas measurements from infrared satellite for chemistry and climate applications, Atmos. Chem. Phys., 3, 14951508, 2003,

\section{SRef-ID: 1680-7324/acp/2003-3-1495.}

Clerbaux, C., Coheur, P.-F., Hurtmans, D., Barret, B., Carleer, M., Colin, R., Semeniuk, K., Mc Connell, J., Boone, C., and Bernath, P.: Carbon monoxide distribution from the ACE solar occultation measurements, Geophys. Res. Lett., 32, L16501, doi:10.1029/2005GL022394, 2005.

Clough, S. A., Shephard, M. W., Mlawer, E. J., Delamere, J. S., Iacono, M. J., Cady-Pereira, K., Boukabara, S., and Brown, P. D.: Atmospheric radiative transfer modeling: a summary of the AER codes, J. Quant. Spectrosc. Radiat. Transfer, 91, 233-244, 2005.

Coheur, P.-F., Barret, B., Turquety, S., Hurtmans, D., Hadji-Lazaro, J., and Clerbaux, C.: Retrieval and characterization of ozone vertical profiles from a thermal infrared tropospheric sounder, J. Geophys. Res., in press, 2005.

Connor, B. J., Siskind, D. E., Tsou, J. J., Parrish, A., and Remsberg, E. E.: Ground-based microwave observations of ozone in the upper stratosphere and mesosphere, J. Geophys. Res., 99, 16757$16770,1994$.
Cooper, O. R., Moody, J. L., Parrish, D. D., Trainer, M., Ryerson, T. B., Holloway, J. S., Hubler, G., Fehsenfeld, F. C., and Evans, M. J.: Trace gas composition of midlatitude cyclones over the western North Atlantic Ocean: A conceptual model, J. Geophys. Res., 107, 4056, doi:10.1029/2001JD000901, 2002a.

Cooper, O. R., Moody, J. L., Parrish, D. D., Trainer, M., Holloway, J. S., Hubler, G., Fehsenfeld, F. C., and Stohl, A.: Trace gas composition of midlatitude cyclones over the western North Atlantic Ocean: A seasonal comparison of O-3 and CO, J. Geophys. Res., 107, 4057, doi:10.1029/2001JD000902, 2002b.

Daniel, J. S. and Solomon, S.: On the climate forcing of carbon monoxide, J. Geophys. Res., 103, 13 249-13 260, 1998.

Deeter, M. N., Emmons L. K., Francis G. L., et al.: Operational carbon monoxide retrieval algorithm and selected results for the MOPITT instrument, J. Geophys. Res., 108, 4399, doi:10.1029/2002JD003186, 2003.

Deeter, M. N., Emmons, L. K., Edwards, D. P., and Gille, J. $\mathrm{C}$.: Vertical resolution and information content of $\mathrm{CO}$ profiles retrieved with MOPITT, Geophys. Res. Lett., 31, L15112, doi:10.1029/2004GL020235, 2004.

Duncan, B. N., Martin, R. V., Staudt, A. C., Yevich, R., and Logan, J. A.: Interannual and seasonal variability of biomass burning emissions constrained by satellite observations, J. Geophys. Res., 108, 4100, doi:10.1029/2002JD002378, 2003

Duncan, B. N. and Bey, I.: A modeling study of export pathways of pollution from Europe: Seasonal and Interannual variations (1987-1997), J. Geophys. Res., 109, D08301, doi:10.1029/2003JD004079, 2004.

Emmons L. K., Hauglustaine D. A., Müller J. F., Carroll M. A., Brasseur G. P., Brunner D., Staehelin J., Thouret V., and Marenco A.: Data composites of airborne observations of tropospheric ozone and its precursors, J. Geophys. Res., 105, 20 497-20 538, 2000.

Forster, C.: Transport of boreal forest fire emissions from Canada to Europe, J. Geophys. Res., 106, 22 887-22 906, 2000.

Frankenberg, C., Platt, U., and Wagner, T.: Retrieval of CO from SCIAMACHY onboard ENVISAT: detection of strongly polluted areas and seasonal patterns in global CO abundances, Atmos. Chem. Phys., 5, 1639-1644, 2005,

\section{SRef-ID: 1680-7324/acp/2005-5-1639.}

Hadji-Lazaro, J., Clerbaux, C., and S. Thiria: An inversion algorithm using neural networks to retrieve atmospheric CO total columns from high-resolution nadir radiances, J. Geophys. Res., 104, 23 841-23 854, 1999.

Hadji-Lazaro, J., Clerbaux, C., Couvert, P., Chazette, P., and Boonne, C.: Cloud filter for CO retrieval from IMG infrared spectra using ECMWF temperatures and POLDER cloud data, Geophys. Res. Lett., 28, 2397-2400, 2001.

Holloway, T., Levy, H., and Kasibhatla, P.: Global distribution of carbon monoxide, J. Geophys. Res., 105, 12 123-12 147, 2000.

Jacob, D. J.: Heterogeneous chemistry and tropospheric ozone, Atmos. Environ., 34, 2131-2159, 2000.

Jacob, D. J., Crawford, J. H., Kleb, M. M., Connors, V. S., Bendura, R. J., Raper, J. L., Sachse, G. W., Gille, J. C., Emmons, L., and Heald, C. L.: Transport and Chemical Evolution over the Pacific (TRACE-P) aircraft mission: Design, execution, and first results, J. Geophys. Res., 108, 9000, doi:10.1029/2002JD003276, 2003.

Jacquinet-Husson, N., Arié E., Ballard, J., Barbe, A., Bjoraker, G., Bonnet, B., Brown, L. R., Camy-Peyret, C., Champion, J. P., 
Chédin, A., et al.: The 1997 spectroscopic GEISA databank, J. Quant. Spectrosc. Radiat. Transfer, 62, 205-254, 1999.

Kar, J., Bremer, H., Drummond, J. R., Rochon, Y. J., Jones, D. B. A., Nichitiu, F., Zou, J., Liu, J., Gille, J. C., Edwards, D. P., Deeter, M. N., Francis, G., Ziskin, D., and Warner, J.: Vertical resolution and information content of $\mathrm{CO}$ profiles retrieved with MOPITT, Geophys. Res. Lett., 31, L23105, doi:10.1029/2004GL021128, 2004.

Kobayashi, H., Shimota, A., Kondo, K., Okumura, E., Kameda, Y., Shimoda, H., and Ogawa, T.: Development and evaluation of theinterferometric monitor for greenhouse gases: a highthroughput Fourier-transform infrared radiometer for nadir Earth observation, Appl. Opt., 38, 6801-6807, 1999.

Martin, R. V., Jacob, D. J., Yantosca, R. M., Chin, M., and Ginoux, P.: Global and regional decreases in tropospheric oxidants from photochemical effects of aerosols, J. Geophys. Res., 108, 4097, doi:10.1029/2002JD002622, 2003.

McMillan, M. W., Barnet, C., Strow, L., Chahine, M. T., McCourt, M. L., Warner, I. X., Novelli, P. C., Korontzi, S., Maddy, E. S., and Datta, S.: Daily global maps of carbon monoxide from NASA's Atmospheric Infrared Sounder, Geophys. Res. Lett., 32, L11801, doi:10.1029/2004GL021821, 2005.

Novelli, P. C., Steele, L. P., and Tans, P. P.: Mixing ratios of carbon monoxide in the troposphere, J. Geophys. Res., 97, 20731$20750,1992$.

Novelli, P. C., Masarie, K. A., and Lang, P. M.: Distributions and recent changes of carbon monoxide in the lower troposphere, J. Geophys. Res., 103, 19015-19033, 1998.

Perrin M. Y. and Hartmann J. M.: Temperature-dependent measurements and modeling of absorption by $\mathrm{CO}_{2}-\mathrm{N}_{2}$ mixtures in the far line-wings of the $4.3 \mu \mathrm{m} \mathrm{CO} 2$ band, J. Quant. Spectrosc. Radiat. Transfer, 42, 311-317, 1989.

Pougatchev, N. S., Jones, N. B., Connor, B. J., et al.: Ground-based infrared solar spectroscopic measurements of carbon monoxide during 1994 Measurement of Air Pollution from Space flights, J. Geophys. Res., 103, 19317-19325, 1998.

Reichle Jr., H. G., Anderson, B. E., Connors, V. S., Denkins, T. C., Forbes, D. A., Gormsen, B. B., Langenfels, R. L., Neil, D. O., Nolf, S. R., Novelli, P. C., Pougatchev, N. S., Roell, M. M., and Steele, L. P.: Space shuttle based global CO measurements during April and October 15 1994, MAPS instrument, data reduction, and data validation, J. Geophys. Res., 104, 21 443-21 454, 1999.
Rodgers, C. D.: Retrieval of atmospheric temperature and composition from remote measurements of thermal radiation, Rev. Geophys. Space Phys., 14(4), 609-624, 1976.

Rodgers, C. D.: Characterisation and error analysis of profiles retrieved from remote sounding measurements, J. Geophys. Res., 95, 5587-5595, 1990.

Rodgers, C. D.: Inverse methods for atmospheric sounding: Theory and Practice, Series on Atmospheric, Oceanic and Planetary Physics - Vol. 2, World Scientific, 2000.

Rothman, L. S., Barbe, A., Benner, D. C., et al.: The HITRAN Molecular Spectroscopic Database: Edition 2000 including Updates through 2001, J. Quant. Spectrosc. Radiat. Transfer, 82, 5-44, 2003.

Russo, R. S., Talbot, R. W., Dibb, J. E., Scheuer, E., Seid, G., Jordan, C. E., Fuelberg, H. E., Sachse, G. W., Avery, M. A., Vay, S. A., Blake, D. R., Blake, N. J., Atlas, E., Fried, A., Sandholm, S. T., Tan, D., Singh, H. B., Snow, J., and Heikes, B. G.: Chemical composition of Asian continental outflow over the western Pacific: Results from Transport and Chemical Evolution over the Pacific (TRACE-P), J. Geophys. Res., 108, 8804, doi:10.1029/2002JD003184, 2003

Stohl, A., Eckhardt, S., Forster, C., James, P., and Spichtinger, N.: On the pathways and timescales of intercontinental air pollution transport, J. Geophys. Res., 107, 4684, doi:10.1029/2001JD001396, 2002

Thompson, A. M.: The Oxidizing Capacity of the Earth's Atmosphere: Probable Past and Future Changes, Science, 256, 11571165, 1992.

Turquety, S., Hadji-Lazaro, J., Clerbaux, C., Hauglustaine, D. A., Clough, S. A., Cassé, V., Schlüssel, P., and Mégie, G.: Operational trace gas retrieval algorithm for the Infrared Atmospheric Sounding Interferometer, J. Geophys. Res., 109, D21301, doi:10.1029/2004JD004821, 2004.

Wang, Y., Jacob, D. J., and Logan, J. A.: Global simulation of tropospheric $\mathrm{O}_{3}-\mathrm{NO}_{\mathrm{X}}$-hydrocarbon chemistry: 1. Model formulation, J. Geophys. Res., 103, 10713-10726, 1998.

Wild, O., Zhu, X., and Prather, M. J.: Fast-J: Accurate simulation of in- and below-cloud photolysis in tropospheric chemistry models, J. Atmos. Chem., 37, 245-282, 2000.

Worden, J., Kulawik, S. S., Shephard, M. W., Clough, S. A., Worden, H., Bowman, K., and Goldman, A.: Predicted errors of tropospheric emission spectrometer nadir retrievals from spectral window selection, J. Geophys. Res., 109, D09308, doi:10.1029/2004JD004522, 2004. 